\title{
Detection of Kinase Translocation Using Microfluidic Electroporative Flow Cytometry
}

\author{
Jun Wang ${ }^{\dagger}$, Ning Bao ${ }^{\dagger}$, Leela L. Paris ${ }^{\ddagger}$, Hsiang-Yu Wang $§$, Robert L. Geahlen ${ }^{\ddagger}$, and Chang \\ Lut, $\boldsymbol{\Upsilon}^{\prime}, \#,{ }^{*}$ \\ † Departments of Agricultural and Biological Engineering, Purdue University, West Lafayette, \\ Indiana 47907, USA \\ ‡ Department of Medicinal Chemistry and Molecular Pharmacology, Purdue University, West \\ Lafayette, Indiana 47907, USA \\ § School of Chemical Engineering, Purdue University, West Lafayette, Indiana 47907, USA \\ I Birck Nanotechnology Center, Purdue University, West Lafayette, Indiana 47907, USA \\ \# Bindley Bioscience Center, Purdue University, West Lafayette, Indiana 47907, USA
}

\section{Abstract}

Directed localization of kinases within cells is important for their activation and involvement in signal transduction. Detection of these events has been largely carried out based on imaging of a low number of cells and subcellular fractionation/Western blotting. These conventional techniques either lack the high throughput desired for probing an entire cell population or provide only the average behaviors of cell populations without information from single cells. Here we demonstrate a new tool, referred to as microfluidic electroporative flow cytometry, to detect the translocation of an EGFP-tagged tyrosine kinase, Syk, to the plasma membrane in B cells at the level of the cell population. We combine electroporation with flow cytometry and observe the release of intracellular kinase out of the cells during electroporation. We found that the release of the kinase was strongly influenced by its subcellular localization. Cells stimulated through the antigen receptor have a fraction of the kinase at the plasma membrane and retain more kinase after electroporation than do cells without stimulation and translocation. We are able to differentiate a cell population with translocation from one without it with the information collected from individual cells of the entire population. This technique potentially allows detection of protein translocation at the single cell level. Due to the frequent involvement of kinase translocations in disease processes such as oncogenesis, our approach will have utility for kinase-related drug discovery and tumor diagnosis and staging.

Translocation of a protein between different subcellular compartments is a common event during signal transduction in living cells. Integrated signaling cascades often lead to the relocalization of protein constituents such as translocations between the cytoplasm and the plasma membrane or nucleus. Such events can be essential for the activation/deactivation and biological function of the protein. The protein-tyrosine kinase, Syk, is a prime example of a protein that translocates to the plasma membrane as part of its role in signal transduction. Syk is essential for the survival, proliferation and differentiation of B lymphocytes, processes regulated by signals sent from the cell surface receptor for antigen (BCR) ${ }^{1,2}$. Syk is the prototype kinase of the Syk/Zap-70 family ${ }^{3,4}$. In mature B cells, clustering of the BCR by

*Corresponding author: changlu@ purdue.edu, Fax: 765-496-1115.

SUPPORTING INFORMATION AVAILABLE: Additional information as noted in text. This material is available free of charge via the Internet at http://pubs.acs.org. 
interactions with antigens (or artificially through interactions with anti-IgM antibodies) leads to recruitment of Syk to the aggregated BCR, which binds to the phosphorylated receptor through a tandem pair of $\mathrm{N}$-terminal SH2 domains and couples the receptor to multiple intracellular signaling networks including the Ras/Erk, phospholipase C $\gamma / \mathrm{NF}-\mathrm{AT}$ and PI3K/ Akt pathways 5,6 .

Determination of the translocation of kinases within cells has been traditionally carried out using methods such as subcellular fractionation/Western blotting or imaging of a few cells. However, when heterogeneous cell populations (e.g., samples derived from primary materials) are studied, it is always beneficial to obtain quantitative information of the entire population at the single cell level to prevent cell subsets from being overlooked. Flow cytometry has been the tool of choice for single cell studies within cell populations of relatively large sizes. However, conventional flow cytometry is intrinsically insensitive to the subcellular location of the probed protein. Laser scanning cytometry (LSC) quantifies nuclear/cytoplasmic distribution of a fluorescent labeled protein based on solid phase cytometry technique ${ }^{7-9}$. The algorithm of quantification based on image analysis is complex and lacks robustness. The throughput is typically less than 100 cells/s, compared to $10^{4}$ cells/s for flow cytometry ${ }^{10}$. Flow cytometric screening of isolated nuclei was also applied to the study of nucleus/cytoplasm translocation ${ }^{11,12}$. This technique requires additional steps to isolate nuclei from living cells and the sample may potentially be contaminated by other organelles. Another technique based on the manipulation of molecular biology inside cells, complementation assay for protein translocation (CAPT), was recently developed ${ }^{13}$. When combined with flow cytometry, it was able to analyze intracellular translocations from the cytoplasm to the nucleus or plasma membrane and interorganelle translocations. Simple and robust high-throughput methods for examining intracellular translocation at the single cell level are highly demanded for mechanistic studies and clinical applications.

Here we demonstrate a new high-throughput technique, which we refer to as electroporative flow cytometry (EFC), to observe the translocation of the kinase Syk from the cytoplasm to plasma membrane at the level of the cell population with information gathered from single cells. Electroporation occurs when cells experience an electrical field with the intensity beyond a certain threshold. During electroporation the electrical field opens up pores in the cell membrane. Such pores allow the release of intracellular materials into the surrounding solution 14-16. In this study, we found that the amount of SykEGFP left in the cells after electroporation was related to whether or not translocation of Syk to the plasma membrane occurred.

Microfluidic EFC was able to detect the translocation of Syk and provide characteristics of the entire cell population in terms of the release of the intracellular kinase. We envision that the same mechanism can be extended to the detection of translocations involving other kinases and cell types.

\section{EXPERIMENTAL SECTION}

\section{Microchip fabrication}

Microfluidic EFC devices were fabricated based on polydimethylsiloxane (PDMS) using standard soft lithography method described before ${ }^{17}, 18$. The microscale patterns were first created using a computer-aided design software (FreeHand MX, Macromedia, San Francisco, $\mathrm{CA}$ ) and then printed out on high-resolution (5080 dpi) transparencies. The transparencies were used as photomasks in photolithography on a negative photoresist (SU-8 2025, MicroChem Corp., Newton, MA). The thickness of the photoresist and hence the depth of the channels was around $33 \mu \mathrm{m}$ (measured by a Sloan Dektak3 ST profilometer). The pattern of channels in the photomask was replicated in SU-8 after exposure and development. The microfluidic channels were molded by casting a layer $(\sim 5 \mathrm{~mm})$ of PDMS prepolymer mixture (General Electric Silicones RTV 615, MG chemicals, Toronto, Ontario, Canada) with a mass ratio of A:B =10:1 
on the photoresist/silicon wafer master treated with tridecafluoro-1,1,2,2-tetrahydrooctyl-1trichlorosilane (United Chemical Technologies, Bristol, PA). The prepolymer mixture was cured at $85^{\circ} \mathrm{C}$ for 2 hours in an oven and then peeled off from the master. Glass slides were cleaned in a basic solution $\left(\mathrm{H}_{2} \mathrm{O}: \mathrm{NH}_{4} \mathrm{OH}(27 \%): \mathrm{H}_{2} \mathrm{O}_{2}(30 \%)=5: 1: 1\right.$, volumetric ratio) at $75^{\circ} \mathrm{C}$ for an hour and then rinsed with DI water and blown dry. The PDMS chip and a glass slide were rendered hydrophilic by oxidizing them using a Tesla coil (Kimble/Kontes, Vineland, NJ) in atmosphere. The PDMS chip was then immediately brought into contact against the slide after oxidation to form closed channels.

\section{Cell sample preparation}

Syk- and Lyn-deficient (Syk/Lyn-deficient) ${ }^{19}$ chicken DT40 B cells (DT40-Syk ${ }^{-}$-Lyn $^{-}$) and SykEGFP-DT40-Syk ${ }^{-}-\mathrm{Lyn}^{-}$cell lines were produced as described before ${ }^{20}$. Briefly, an XhoI/ $\mathrm{HpaI}$ DNA fragment encoding Syk was cut from EPB:SykMyc ${ }^{21}$. Insertion of this fragment into XhoI/SmaI sites of the pEGFP-N2 vector (Clontech, Palo Alto, CA) resulted in a fusion of Syk and enhanced GFP (SykEGFP). DT40-Syk ${ }^{-}$Lyn $^{-}$cells $\left(1 \times 10^{6}\right)$ were transfected with $20 \mu \mathrm{g}$ of the DNA construct as previously described to produce SykEGFP-DT40-Syk ${ }^{-}$$\mathrm{Lyn}^{-22}$. Both DT40 cell lines were cultured for at least 15 passages in complete medium (RPMI 1640 media supplemented with $10 \%$ heat-inactivated fetal calf serum, $1 \%$ chicken serum, 50 $\mu \mathrm{M}$ 2-mercaptoethanol, $1 \mathrm{mM}$ sodium pyruvate, $100 \mathrm{IU} / \mathrm{ml}$ penicillin $\mathrm{G}$, and $100 \mu \mathrm{g} / \mathrm{ml}$ streptomycin) before the experiment in microfluidic EFC devices. After $48 \mathrm{~h}$ subculture, cells were harvested and suspended in serum free electroporation buffer $\left(1 \mathrm{mM} \mathrm{MgSO}_{4}, 8 \mathrm{mM}\right.$ $\mathrm{Na}_{2} \mathrm{HPO}_{4}, 2 \mathrm{mM} \mathrm{KH}{ }_{2} \mathrm{PO}_{4}$, and $250 \mathrm{mM}$ sucrose, $\left.\mathrm{pH}=7.2\right)$. One half of the cells $\left(10^{6}\right.$ cells $\left./ \mathrm{ml}\right)$ were kept unstimulated, while the other half were stimulated with $50 \mu \mathrm{g} / \mathrm{ml}$ goat anti-chicken immunoglobulin M (IgM) antibody (Bethyl Laboratories, Montgomery, TX) for $1 \mathrm{~h}$ at $20^{\circ} \mathrm{C}$.

To establish a negative control (Figure S4c and Figure 5c), both stimulated and unstimulated DT40-Syk ${ }^{-}-\mathrm{Lyn}^{-}$were labeled with a fluorogenic dye, calcein AM (Invitrogen, Carlsbad, CA) after the above procedure for $1 \mathrm{~h}$ stimulation or incubation. The labeling was done by incubating the cells with calcein $\mathrm{AM}$ at a concentration of $20 \mathrm{ng} / \mathrm{ml}$ for $10 \mathrm{~min}$.

All cell samples were centrifuged at $300 \times g$ for 10 min before microfluidic EFC experiment with a final cell density of $10^{7}$ cells $/ \mathrm{ml}$ in the electroporation buffer described above.

\section{Fluorescence microscopy}

The microfluidic device was mounted on an inverted fluorescence microscope (IX-71, Olympus, Melville, NY) with a $40 \mathrm{X}$ dry objective $(\mathrm{NA}=0.60)$. The epifluorescence excitation was provided by a $100 \mathrm{~W}$ mercury lamp, together with brightfield illumination. The excitation and emission from SykEGFP-expressing cells or cells labeled with calcein AM (Molecular Probes, Eugene, OR) were filtered by a fluorescence filter cube (exciter HQ480/40, emitter HQ535/50, and beamsplitter Q505lp, Chroma technology Corp., Rockingham, VT).

For the observation of cells after electroporation, cells were transferred from the microchip reservoir to a 96 well plate and then centrifuged for $10 \mathrm{~min}$ at $300 \times g$ to settle the cells to the bottom before imaging under the microscope. For the real-time observation of kinase translocation in live cells, cell samples were immediately placed on cover slips after adding $50 \mu \mathrm{g} / \mathrm{ml}$ goat anti-igM antibody in the electroporation buffer $\left(1 \mathrm{mM} \mathrm{MgSO}_{4}, 10 \mathrm{mM}\right.$ phosphate buffer, and $250 \mathrm{mM}$ sucrose, $\mathrm{pH}=7.2$ ) containing the cells.

\section{Microchip operation and signal detection}

The setup of the apparatus is shown in Figure 1. The microfluidic EFC device was mounted on an inverted fluorescence microscope (IX-71, Olympus, Melville, NY) with a 40X dry objective $(\mathrm{NA}=0.60)$. Prior to the experiment, the microfluidic channel was flushed with the 
electroporation buffer for $15 \mathrm{~min}$ to condition the channel and remove impurities. The 3 inlets of the channel were connected to a syringe pump (PHD infusion pump, Harvard Apparatus, Holliston, MA) through plastic tubing. The volumetric flow rates were set at $1 \mu \mathrm{l} / \mathrm{min}$ for the sample channel inlet and $5 \mu \mathrm{l} / \mathrm{min}$ for each of two side channel inlets. With a cell density of $10^{7}$ cells $/ \mathrm{mL}, 100-200$ cells flowed through the laser detection spot and were detected by a photomultiplier tube per second (the throughput fluctuated due to the uneven density of cells across the liquid volume). The number of cells scanned was reflected by the number of peaks in the raw data (signal detected by the photomultiplier tube). A high voltage power supply (PS350, Stanford Research Systems, Sunnyvale, CA) was used to generate a constant direct current (DC) voltage in between the sample and the outlet reservoirs.

An air-cooled 100mW argon ion laser (Spectra-Physics, Mountain View, CA) at $488 \mathrm{~nm}$ was applied as the excitation source for laser-induced fluorescence. The laser beam was spectrally filtered by a 10LF10-488 bandpass filter (Newport Corp., Irvine, CA) before its intensity was adjusted by neutral density filters (Newport Corp., Irvine, CA). The laser was introduced into the microscope through laser port B (Olympus, Melville, NY) and a fluorescence filter cube (505DCLP dichroic beamsplitter, D535/40 emission filter, Chroma Technology Corp., Rockingham, VT) before it was finally focused by the objective into the microfluidic channel. The emission light was collected by the same objective and converted into current by a photomultiplier tube (R9220, Hamamatsu, Bridgewater, NJ) biased at $730 \mathrm{~V}$. The photocurrent was amplified by a low noise current preamplifier (SR570, Standard Research System, Sunnyvale, California) with the cutoff frequency and sensitivity set at $30 \mathrm{~K} \mathrm{~Hz}$ and $100 \mu \mathrm{A} / \mathrm{V}$, respectively. The current was then converted to voltage and input into a PCI data acquisition card (PCI-6254, National Instruments, Austin, TX) operated by LabView software (National Instruments, Austin, TX). The data were processed by programs written in MATLAB to extract histograms of the fluorescence from a cell population. The data were presented in 4 decades (from 0.001 to $10 \mathrm{~V}$ ) logarithmic histograms with 256 channels. The voltage signal ranging from $1 \mathrm{mV}$ to $10 \mathrm{~V}$ was converted to 4 decade logarithmic voltage scale and then 256 scale channels.

\section{Conventional flow cytometry}

We also conducted screening of the chicken DT40 cells (stimulated and unstimulated) using a commercial flow cytometer with $488 \mathrm{~nm}$ excitation and FL-1 $525 \mathrm{~nm}$ BP emission filter (Cytomics $^{\text {TM }}$ FC 500 flow cytometer, Beckman Coulter, Inc., Fullerton, CA) at the Purdue University Flow Cytometry Laboratories. For each run, around 10000 cells were screened for fluorescence intensity.

\section{Western blot analysis}

SykEGFP-DT40-Syk ${ }^{-}$Lyn $^{-}$cells $\left(1 \times 10^{6}\right.$ cells $\left./ \mathrm{ml}\right)$ were treated with or without $50 \mu \mathrm{g} / \mathrm{ml}$ anti-IgM antibody under the conditions described in "cell sample preparation". The cells were recovered and permeabilized by incubation in a buffer containing $0.1 \%$ digitonin, $250 \mathrm{mM}$ sucrose and $1 \mathrm{mM}$ EDTA. The particulate (membrane) fraction was collected by centrifugation at $1000 \times g$, washed once with digitonin free lysis buffer and solubilized in sodium dodecyl sulfate (SDS)-sample buffer to release proteins. The proteins in both soluble (cytosolic) fraction and particulate (membrane) fraction were separated by sodium dodecyl sulfatepolyacrylamide gel electrophoresis (SDS-PAGE), transferred to polyvinylidene difluoride (PVDF) membranes and detected by Western blotting with an anti-Syk antibody (N-19, Santa Cruz Biotechnology, Santa Cruz, CA).

\section{Fluorescence intensity calibration}

We used Molecules of Equivalent Soluble Fluorophores (MESF) units to quantify the fluorescence intensity from single cells when microfluidic EFC was used ${ }^{23,24}$. A standard 
curve was first established by screening beads with different predefined fluorescence quantities (high level Quantum FITC MESF Kits, Bangs La borotories, Inc., Fishers, IN) using our microfluidic EFC devices. The peak channel numbers of beads was plotted against their known MESF values (Figure S3b in Supporting Information). The mean percentage of EGFP or calcein of a cell population, $\mathrm{P}_{\mathrm{EGFP}}$, (by assuming that SykEGFP-DT40-Syk ${ }^{-} \mathrm{Lyn}^{-}$population without electroporation has a mean percentage of 1 and DT40-Syk ${ }^{-}-\mathrm{Lyn}^{-}$population has a mean percentage of 0$)$ was calculated using following formulae $(\Phi=$ fluorescence quantum yield, $\varepsilon=$ extinction coefficient, $A=$ absorbance, peak $A_{E G F P}=489 \mathrm{~nm}$, peak $A_{\text {Fluorescein }}=495 \mathrm{~nm}$, $\mathrm{V}=$ average cell volume, $\mathrm{EGFP}_{\text {mean }}=$ the population mean MESF value of EGFP fluorescence signal interpolated from the standard curve (Figure S3b in Supporting Information),

$$
[\mathrm{EGFP}]=\mathrm{EGFP}_{\text {mean }} \times \mathrm{B} \times \mathrm{K} / \mathrm{V}
$$

Where $\mathrm{B}=\Phi_{\mathrm{EGFP}} \times{ }_{\varepsilon \mathrm{EGFP}} \times \mathrm{A}_{\mathrm{EGFP}: 488 \mathrm{~nm}} / \mathrm{A}_{\mathrm{EGFP}: 484 \mathrm{~nm}} /$ $\left(\Phi_{\text {Fluorescein }} \times \varepsilon_{\text {Fluorescein }} \times A_{\text {Fluorescein:488nm }} / A_{\text {Fluorescein:490nm }}\right)$ From the standard curve, $K=$ moles fluorescein/relative fluorescent units. $[\mathrm{EGFP}]_{\mathrm{control}}$ is the value for DT40-Syk ${ }^{-} \mathrm{Lyn}^{-}$ population (without EGFP tagging and without electrical field), $[\mathrm{EGFP}]_{\mathrm{E}=0}$ is the value for SykEGFP-DT40-Syk ${ }^{-}$Lyn $^{-}$population without the electrical field. By assuming constant B, $\mathrm{K}$ and $\mathrm{V}$ under different electric field, $\mathrm{P}_{\mathrm{EGFP}}$ of a cell population can be calculated to be

$$
\mathrm{P}_{\mathrm{EGFP}}=\frac{\left([\mathrm{EGFP}]-[\mathrm{EGFP}]_{\text {Control }}\right)}{\left([\mathrm{EGFP}]_{\mathrm{E}=0}-[\mathrm{EGFP}]_{\text {Control }}\right)} \times 100 \%
$$

The average percentage of calcein in a given cell population was calculated using the same method.

\section{RESULTS}

The design and setup of the microfluidic EFC device is shown in Figure 1. The device consisted of two intersecting microfluidic channels connected to four reservoirs (Figure 1a). The cell sample flowed through the horizontal channel from the sample reservoir to the outlet reservoir, carried by a pressure-driven flow generated by a syringe pump (Figure 1b). In order to screen cells at the single cell level, hydrodynamic focusing was applied by having the buffer flow into the horizontal channel from the two vertical channels at equal flow rates (supported by a second syringe pump). To incorporate electroporation into the device, two platinum electrodes connected to a DC power supply were inserted in the sample and outlet reservoirs to establish an electrical field across the horizontal channel. A new microfluidic electroporation technique based on constant DC voltage was applied here ${ }^{16,18}$. The horizontal channel was composed of two wide sections $\left(\mathrm{W}_{1}=300 \mu \mathrm{m}\right)$ and one narrow section $\left(\mathrm{W}_{2}=30 \mu \mathrm{m}\right)$ with the depth of the whole channel being uniform (Figure 1a). The field strength in the narrow section was approximated to be 10 times higher than the field strength in the wide sections according to Ohm's law, which predicts that the field strength in each section is inversely proportional to the cross-sectional area in the section under a constant DC voltage. A similar field intensity distribution in the channel was modeled in our previous work ${ }^{25}$. We have shown that when the overall voltage is in the right range, electroporation exclusively occurs in the narrow section since the field intensity in the wide sections are too weak to compromise the cell membrane 16,18 . The field in the reservoirs is negligible due to the large size of the volume in there. In such a flow-through electroporation device, the duration for cells to stay in the narrow section (the electroporation section) of the channel was determined by their velocity and the length of 
the section. The velocity of cells here was determined mostly by the infusion rate of the syringe pump. The electrical field has very little effect on the velocity (Figure S1 in Supporting Information). The laser detection point was positioned in the narrow section after the point where hydrodynamic focusing occurred (Figure 1a). This special constant-voltage based electroporation technique provided a unique design for treating single cells uniformly when a stable flow was established. The microfluidic EFC device was fabricated on PDMS/glass slide using standard soft lithography as we demonstrated previously 18 .

Syk-deficient chicken DT40 cells expressing a fusion protein consisting of Syk coupled to EGFP, SykEGFP, has been shown to respond to anti-IgM antibody stimulation by translocating from cytoplasmic and nuclear compartments to the cross-linked B cell antigen receptor (BCR) at the plasma membrane ${ }^{20}$.I n SykEGFP-expressing DT40 cells lacking Syk, treatment with anti-IgM antibody leads to rapid clustering and redistribution of receptor-Syk complexes that form a cap at one pole of the cell ${ }^{20}$. In the absence of Lyn, the receptor-Syk complexes can persist at the inner side of cell membrane without being internalized for more than $1 \mathrm{~h}$ at $37^{\circ}$ $\mathrm{C}^{20}$. Such caps are indicative of the translocation to the plasma membrane.

In our experiment, we applied SykEGFP-expressing chicken DT40 cells lacking both Syk and Lyn to ensure that the localization of Syk at the plasma membrane lasted long enough for us to finish the tests. The cells were stimulated at room temperature $\left(20^{\circ} \mathrm{C}\right)$ by anti-IgM antibody. Fluorescence images were taken at timed intervals of $0.5 \mathrm{~h}$. Figure 2 shows that the cells started to show patches and caps of fluorescent clusters at $5 \mathrm{~min}$ (Figure 2a). A large percentage of cells started to form caps at their poles around $30 \mathrm{~min}$ after the stimulation. Within $60 \mathrm{~min}$ the vast majority of cells had a single cap at one pole. After stimulation for $60 \mathrm{~min}$, the caps were stable staying on the membrane. The majority of the cells ( 81\%) exhibited obivious capping at around $1 \mathrm{~h}$ after anti-IgM antibody stimulation, which is very comparable to the results previously reported ${ }^{20}$. The translocation was further confirmed using Western blot analysis under the same stimulation conditions (Figure S2 in Supporting Information). Based on these results, we carried out microfluidic EFC tests on SykEGFP-DT40-Syk ${ }^{-}$Lyn $^{-}$cells at room temperature $\left(20^{\circ} \mathrm{C}\right) 1 \mathrm{~h}$ after stimulation with anti-IgM when translocation to the plasma membrane was desired.

Conventional flow cytometry is intrinsically insensitive to the subcellular location of the protein of interest. We confirmed that using both a commercial flow cytometer and our microfluidic EFC device with zero voltage. Figure 3 shows the event frequency versus the fluorescence intensity for the cell populations with and without anti-IgM stimulation. With a commercial flow cytometer the mean fluorescence intensity of the cell population with translocation (after anti-IgM stimulation) was 19.6 compared to 19.2 for the cell population without stimulation, on a 0.1 to 1000 logarithmic relative brightness scale $(10,000$ cells in each population). The histograms of the two cell populations overlapped very well. When screening the cells in our microfluidic device, the two cell populations $(2,000 \sim 3000$ cells in each, population) with and without stimulation also overlapped with the mean channels being 159 and 160, respectively. Two different log scales were used in the software with the commercial flow cytometer and in our data analysis of the microfluidic flow cytometer. The two scales in Figure $3 \mathrm{a}$ and $3 \mathrm{~b}$ are completely interchangeable ${ }^{26}$. The results indicate that the translocation cannot be detected with conventional flow cytometry approach using either a commercial flow cytometer or our microfluidic flow cytometer. The difference between the control and the sample is larger in the data taken by the commercial flow cytometer than that taken by the microfluidic cytometer. The commercial flow cytometer applied gating procedure by software which removed the data from dead cells (determined based on scatter properties) before generating the histograms while the histograms generated by the microfluidic flow cytometer included every cell flowing through. The two systems are also different in the detectors, filters, 
and signal processing. The commercial flow cytometry handled more cells than the microfluidic flow cytometer due to its higher velocity and throughput.

We applied microfluidic EFC to analyze the cell populations with and without anti-IgM stimulation, under varying voltages across the sample and outlet reservoirs. The field intensity in the narrow section changed from 0 to $1100 \mathrm{~V} / \mathrm{cm}$ as calculated based on Ohm's law. The field intensity in the wide sections was only about $1 / 10$ of that in the narrow section. Electroporation occurred exclusively in the narrow section in all these experiments since we have shown that the field intensity lower than $\sim 300-400 \mathrm{~V} / \mathrm{cm}$ does not introduce electroporation of mammalian cells using the same microfluidic electroporation technique, based on the observation of the internalization of impermeant molecules and the cell size expansion ${ }^{16,18}$. The fluorescence intensity from single cells was recorded at the laser focal volume that was close to the exit of the narrow section. The detected signal represented the amount of SykEGFP left in each cell after the electroporation. There could be minor interference with the fluorescence signal from the released fluorescent molecules. However, due to the small focal volume ( $\sim 3 \mu \mathrm{m}$ across) and the rapid dilution in the fairly large channel ( $33 \mu \mathrm{m} \times 33 \mu \mathrm{m}$ in the cross section), such effect is not pronounced. In Figure 4, we show the histograms of the fluorescence intensity generated by SykEGFP-DT40-Syk ${ }^{-}$-Lyn ${ }^{-}$cells (without stimulation) processed in the microfluidic EFC device at different field intensities (the field duration was $60 \mathrm{~ms}$ ). We were able to see significant and continuous decrease in the fluorescence intensity of the cells when the field intensity increased from 0 to $1100 \mathrm{~V} / \mathrm{cm}$ due to increased electroporative release of the fluorescent protein. This indicates that the released SykEGFP was diluted in the solution drastically and did not add to the fluorescence intensity of cells in a significant way. Figure S4 (in Supporting Information) shows histograms of the fluorescence intensity from cell populations treated under different conditions and electroporated under different electrical parameters. In each histogram, the y axis shows the percentile frequency of detection and the $\mathrm{x}$ axis represents the fluorescence intensity (in channels). In Figure S4a, we show the histograms of the fluorescence intensity generated by the cell samples stimulated by anti-IgM (blue) and those that were not stimulated (red), in the microfluidic EFC device with $\mathrm{L}_{2}$ of $2 \mathrm{~mm}$. Assuming no effects from the electrical field on the velocity of cells (such effects are in general minor when the velocity of the carrier flow is high as shown in Figure S1 in Supporting Information), the cells stayed in the narrow section for around $120 \mathrm{~ms}$ at this flow rate of $1 \mu \mathrm{L} / \mathrm{min}$. When we increased the field intensity in the narrow section from 0 to $900 \mathrm{~V} / \mathrm{cm}$, the fluorescence intensity of the cell population (stimulated with anti-IgM or not) shifted to the lower end. The translocation did not make any difference in the histogram until the field intensity increased to $600 \mathrm{~V} / \mathrm{cm}$. At this field intensity the two histograms did not totally overlap and the stimulated cell population had a slightly higher fluorescence intensity compared to that of the other population without stimulation and translocation. This difference increased further when we increased the field intensity to 700 and $800 \mathrm{~V} / \mathrm{cm}$. At $900 \mathrm{~V} / \mathrm{cm}$, the two histograms overlapped again with the mean fluorescence intensity at 128 and 130. When these values were compared to the mean of the control cell population without EGFP-labeling (DT40-Syk ${ }^{-} \mathrm{Lyn}^{-}$) at 117, it appeared that the depletion of SykEGFP was not complete at $900 \mathrm{~V} / \mathrm{cm}$ and $120 \mathrm{~ms}$.

To observe the effects of the duration of time spent in the electroporation field on the release of SykEGFP, we applied a microfluidic EFC device with $\mathrm{L}_{2}$ of $1 \mathrm{~mm}$. With the flow rates kept the same as in the previous experiment, the electroporation duration before detection was only half of that in the first experiment under the same field intensity. Figure S4b (in Supporting Information) shows that the two histograms from the cell populations with and without stimulation overlapped very well up to $700 \mathrm{~V} / \mathrm{cm}$. Difference between the two histograms started to show up at $800 \mathrm{~V} / \mathrm{cm}$ and reached a maximum at around $1000 \mathrm{~V} / \mathrm{cm}$ before the two histograms were not distinguishable again at $1100 \mathrm{~V} / \mathrm{cm}$. Compared to the data in Figure S4a, with the electroporation duration at one half, a higher field intensity was needed to achieve a 
similar level of differentiation between the stimulated cell population and the unstimulated one. In both Figure S4a and b, the difference between the two cell populations was the most pronounced in the medium range of the field intensity. Such a difference was not present without the electric field and it diminished at very high field intensity. To confirm that such differentiation was not caused by the interaction between the plasma membrane and the antibody, we also did the same experiment with DT40-Syk $-\mathrm{Lyn}^{-}$cells that were not labeled by expression of SykEGFP, but were instead stained with Calcein AM. In live cells, the nonfluorescent calcein AM is converted to green fluorescent calcein, after acetoxymethyl ester hydrolysis by intracellular esterases. As shown in Figure S4c (in Supporting Information), we did not observe a significant difference between the cell population with added anti-IgM and the population without the antibody at any field intensity. This confirms that the differentiation was closely related to the translocation of SykEGFP.

Figure 5 shows the mean fluorescence intensity of the cell population plotted against the field intensity for all the three experiments in Figure S4. It was found that the optimal field intensities for detecting translocation to the plasma membrane in a cell population was around 700 and $800 \mathrm{~V} / \mathrm{cm}$ with a duration of $120 \mathrm{~ms}$ or $1000 \mathrm{~V} / \mathrm{cm}$ with a duration of $60 \mathrm{~ms}$ (significantly different at $\mathrm{P}<0.01)$.

We have also taken both phase contrast and fluorescent images of the cells after being processed in the microfluidic EFC device (Figures S5 and S6 in Supporting Information). The cell size after the tests became increasingly larger when the field intensity increased, due to the influx of the surrounding solution during electroporation. The residual fluorescence from the cells decreased with increasing field intensity. No significant fragmentation of the plasma membrane was observed. There was some sign of possible membrane fragments only at the highest field intensity (e.g. in Figures S5f and S6f).

\section{DISCUSSION}

We have observed the rapid release of intracellular contents during electroporation in similar devices with alternating wide and narrow sections in our previous work ${ }^{16,18,25}$. Such release is due to a combination of outward diffusion and electrophoretic motion of intracellular molecules when the plasma membrane is compromised by the electrical field. Our results from this study indicate that the electroporative release of an intracellular protein is related to the activation state of the cell and the protein's interaction with the subcellular structures. We propose that the binding between Syk and the phosphorylated receptor through a tandem pair of N-terminal SH2 domains was responsible for the higher retention of Syk molecules in the cell population with the translocation to the plasma membrane. Electrical parameters have strong influences on the extent to which a cell population with translocation can be differentiated from one without it. It needs to be noted that our method reveals the fraction of the fluorescently labeled kinase being released during electroporation without differentiating among several possible mechanisms contributing to the retention of the kinase (with the kinase translocation to the plasma membrane being one of them).

The accuracy of our technique is largely dependent on the percentage of the kinase undergoing translocation to the plasma membrane. This is in turn related to the number of available binding sites on the plasma membrane. The data also suggested that, although the differentiation of stimulated and unstimulated cells initially increased with the field intensity and duration, at very high field intensities such difference diminished, possibly reflecting dissociation of the complex from the plasma membrane due to the extensive electroporation in the majority area of the membrane or damage to the binding from Joule heating. In this study the release of the fluorescent protein (SykEGFP) was not complete even for the unstimulated cell population without translocation $(25.9 \%-28.6 \%$ of the fluorescent protein left in cells with the highest 
field intensities applied as shown in Figure S3 in Supporting Information), suggesting that a fraction of the kinase remained in the cytoplasm, the nucleus, or other subcellular compartments at the moment of the detection. More complete release might be attainable by the optimization of the electroporation conditions other than the electrical parameters (e.g. osmolarity of the electroporation medium) ${ }^{16}$.

By combining electroporation with flow cytometry, we demonstrate microfluidic EFC as a new tool to differentiate cell populations with different activation states. Microfluidic EFC offers a simple and robust physical tool for detecting kinase translocation within the scope of the entire cell population. In principle, there are no intrinsic limitations that prevent our technology from having the throughput and the stability similar to those of conventional flow cytometry. The time required for the electroporative release of the intracellular materials from cells does not necessarily put a limitation on the throughput. In principle, the length of the narrow section can be increased to maintain enough duration for the electroporative release of intracellular materials while both the throughput and the velocity of the cells are high. The microfluidic platform is well suited for both research and clinical settings.

\section{Supplementary Material}

Refer to Web version on PubMed Central for supplementary material.

\section{Acknowledgments}

We thank Purdue University and grant CA37372 from the National Cancer Institute for the financial support.

\section{References}

1. Takata M, Sabe H, Hata A, Inazu T, Homma Y, Nukada T, Yamamura H, Kurosaki T. EMBO J 1994;13:1341-1349. [PubMed: 8137818]

2. Turner M, Mee PJ, Costello PS, Williams O, Price AA, Duddy LP, Furlong MT, Geahlen RL, Tybulewicz VL. Nature 1995;378:298-302. [PubMed: 7477352]

3. Zioncheck TF, Harrison ML, Geahlen RL. J Biol Chem 1986;261:15637-15643. [PubMed: 3782080]

4. Zioncheck TF, Harrison ML, Isaacson CC, Geahlen RL. J Biol Chem 1988;263:19195-19202. [PubMed: 3198621]

5. Campbell KS. Curr Opin Immunol 1999;11:256-264. [PubMed: 10375554]

6. DeFranco AL. Curr Opin Immunol 1997;9:296-308. [PubMed: 9203421]

7. Deptala A, Bedner E, Gorczyca W, Darzynkiewicz Z. Cytometry 1998;33:376-382. [PubMed: 9822350]

8. Bedner E, Li X, Kunicki J, Darzynkiewicz Z. Cytometry 2000;41:83-88. [PubMed: 11002262]

9. Ozawa K, Hudson CC, Wille KR, Karaki S, Oakley RH. Cytometry A 2005;65A:69-76. [PubMed: 15778994]

10. Pozarowski, P.; Holden, E.; Darzynkiewicz, Z. Cell Imaging Techniques: Methods and Protocols. Taatjes, DJ.; Mossman, BT., editors. Vol. 319. Humana Press; Totowa, NJ: 2005. p. 165-192.

11. Blaecke A, Delneste Y, Herbault N, Jeannin P, Bonnefoy JY, Beck A, Aubry JP. Cytometry 2002;48:71-79. [PubMed: 12116367]

12. Cognasse F, Sabido O, Genin C, Garraud O. Immunol Lett 2003;90:49-52. [PubMed: 14611907]

13. Wehrman TS, Casipit CL, Gewertz NM, Blau HM. Nat Methods 2005;2:521-527. [PubMed: 15973423]

14. Rols MP, Teissie J. Biophys J 1990;58:1089-1098. [PubMed: 2291935]

15. Wang HY, Lu C. Chem Commun 2006:3528-3530.

16. Wang HY, Lu C. Biotechnol Bioeng 2006;95:1116-1125. [PubMed: 16817188]

17. Duffy DC, McDonald JC, Schueller OJA, Whitesides GM. Anal Chem 1998;70:4974-4984.

18. Wang HY, Lu C. Anal Chem 2006;78:5158-5164. [PubMed: 16841942] 
19. Takata M, Kurosaki T. J Exp Med 1996;184:31-40. [PubMed: 8691147]

20. Ma H, Yankee TM, Hu JJ, Asai DJ, Harrison ML, Geahlen RL. J Immunol 2001;166:1507-1516. [PubMed: 11160190]

21. Keshvara LM, Isaacson C, Harrison ML, Geahlen RL. J Biol Chem 1997;272:10377-10381. [PubMed: 9099676]

22. Keshvara LM, Isaacson CC, Yankee TM, Sarac R, Harrison ML, Geahlen RL. J Immunol 1998;161:5276-5283. [PubMed: 9820500]

23. Wang LL, Gaigalas AK, Abbasi F, Marti GE, Vogt RF, Schwartz A. J Res Natl Inst Stand Technol 2002;107:339-353.

24. Martin BR, Giepmans BNG, Adams SR, Tsien RY. Nat Biotechnol 2005;23:1308-1314. [PubMed: 16155565]

25. Wang J, Lu C. Appl Phys Lett 2006;89:234102.

26. Shapiro, HM. Practical flow cytometry. 4. John Wiley \& Sons; Hoboken, New Jersey: 2003. 

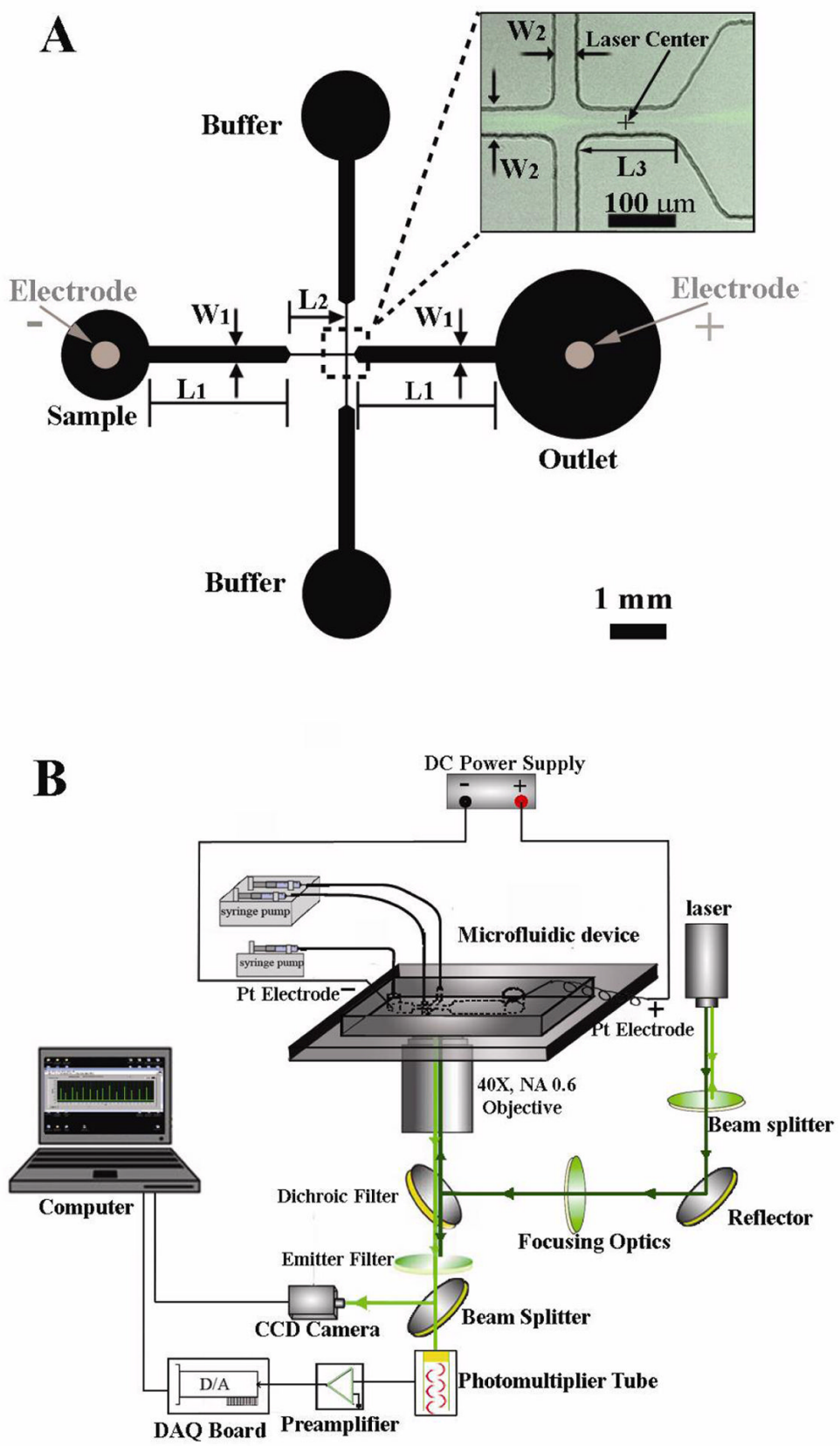

Figure 1.

(a) The layout of the microfluidic chip. The width varied in the horizontal channel with $\mathrm{W}_{1}$ of $300 \mu \mathrm{m}$ and $\mathrm{W}_{2}$ of $33 \mu \mathrm{m}$. The length of the narrow section $\mathrm{L}_{2}$ was set as either 1 or $2 \mathrm{~mm}$ in different experiments. The other sections in the horizontal channel had a length of $2.5 \mathrm{~mm}$ for $\mathrm{L}_{1}$ and $150 \mu \mathrm{m}$ for $\mathrm{L}_{3}$. The depth of the microfluidic channels was uniformly $33 \mu \mathrm{m}$. The laser detection point was positioned at the center of the horizontal channel after hydrodynamic focusing. In the inset image, the fluorescent trail was left by SykEGFP-DT40-Syk ${ }^{-}$Lyn $^{-}$cells when the ratio between the flow rate in one of the two vertical channels and that in the horizontal channel was 3:1. (b) A schematic illustration of the setup of the microfluidic electroporative flow cytometry apparatus. 

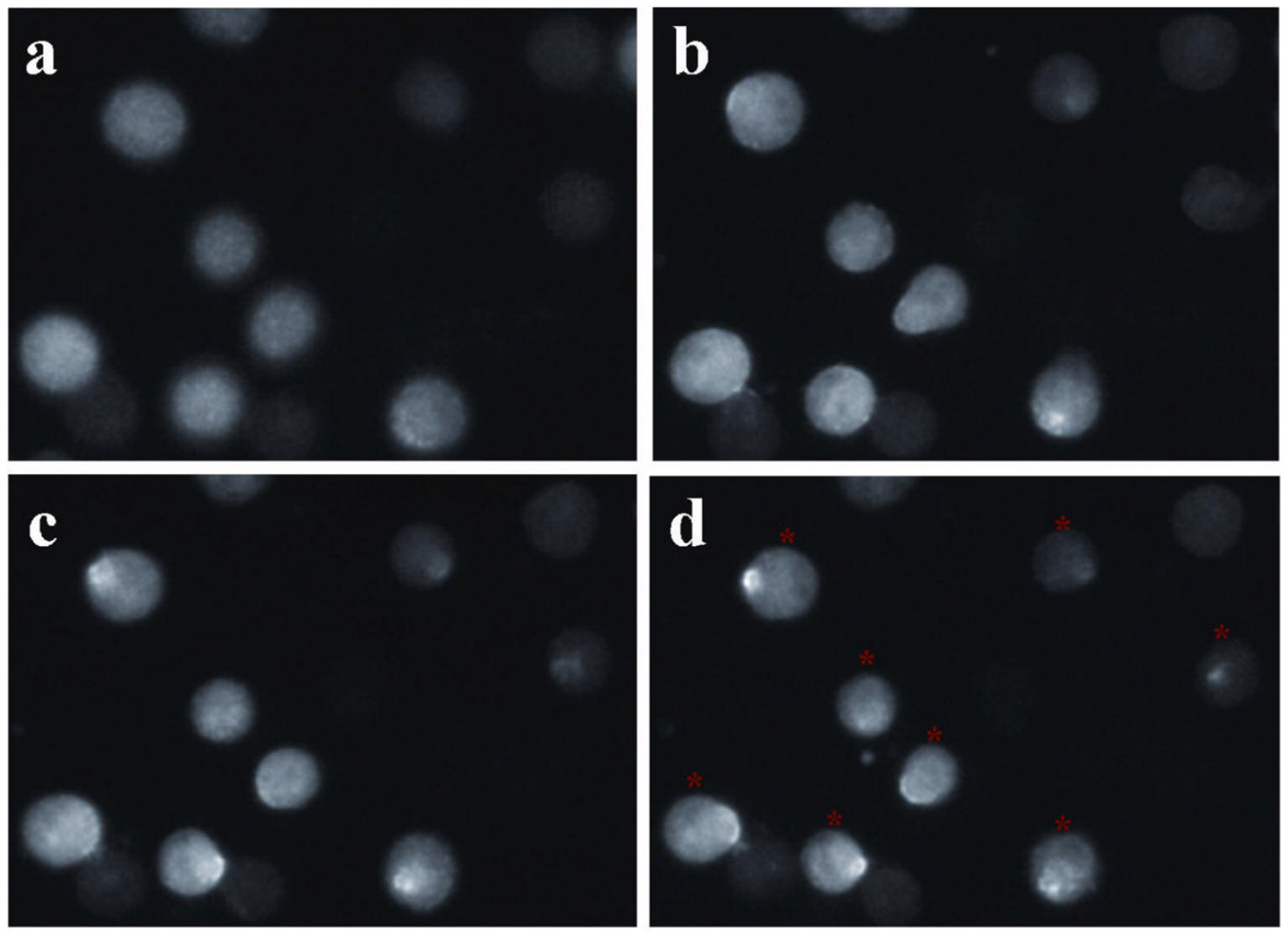

Figure 2.

The fluorescent images showing capping of SykEGFP at the plasma membrane. SykEGFP was redistributed to the plasma membrane after stimulation with anti-IgM antibody at room temperature for $5 \mathrm{~min}(\mathbf{a}), 30 \mathrm{~min}(\mathbf{b}), 60 \mathrm{~min}(\mathbf{c})$ and $90 \mathrm{~min}(\mathbf{d})$. The cells labeled by red asterisks in (d) were considered the ones with capping. The percentage of cells with capping was $81 \pm 3 \%$ (enumerated in three separate experiments by one observer with the results of 396/470, 462/575, and 388/497). 

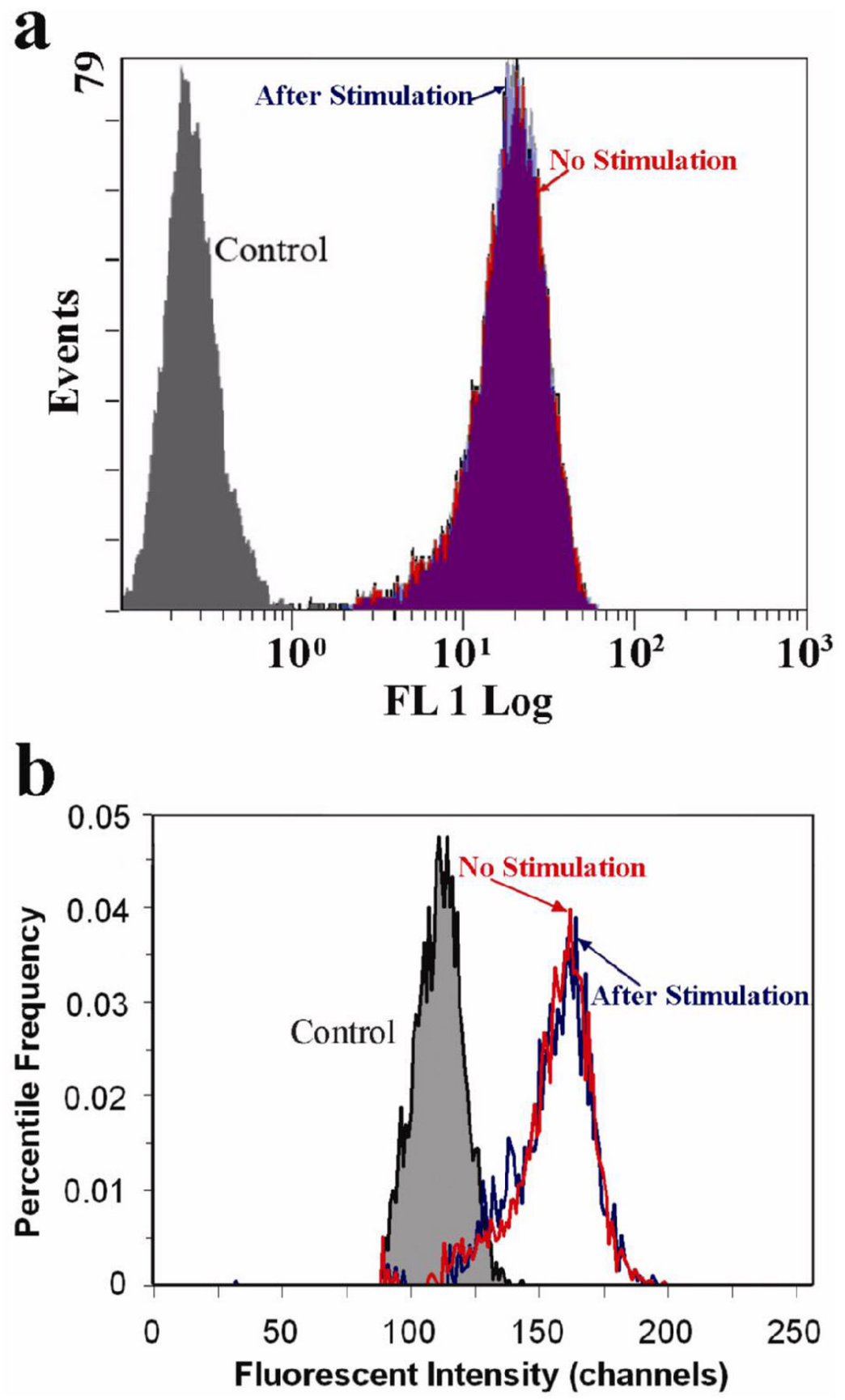

Figure 3.

The histograms of the fluorescent intensity of SykEGFP-DT40-Syk ${ }^{-}-\mathrm{Lyn}^{-}$cells with and without stimulation by anti-IgM antibody and the DT40-Syk ${ }^{-}-\mathrm{Lyn}^{-}$cells (the control). (a) Histograms obtained by Cytomics FC 500 Flow cytometer (Red: without stimulation; Blue: stimulated by anti-IgM; Grey: the control, DT40-Syk ${ }^{-} \mathrm{Lyn}^{-}$cells without EGFP labeling). The data generated by dead cells (determined based on scatter properties) were excluded from the analysis. (b) Analysis of the same samples as in (a) in the microfluidic device (with the voltage at 0). To eliminate the effect of different cell sample sizes on the shape of the histograms, the distributions were normalized to have percentile frequency (the frequency divided by the total number of observations) for the $\mathrm{y}$-axis. 


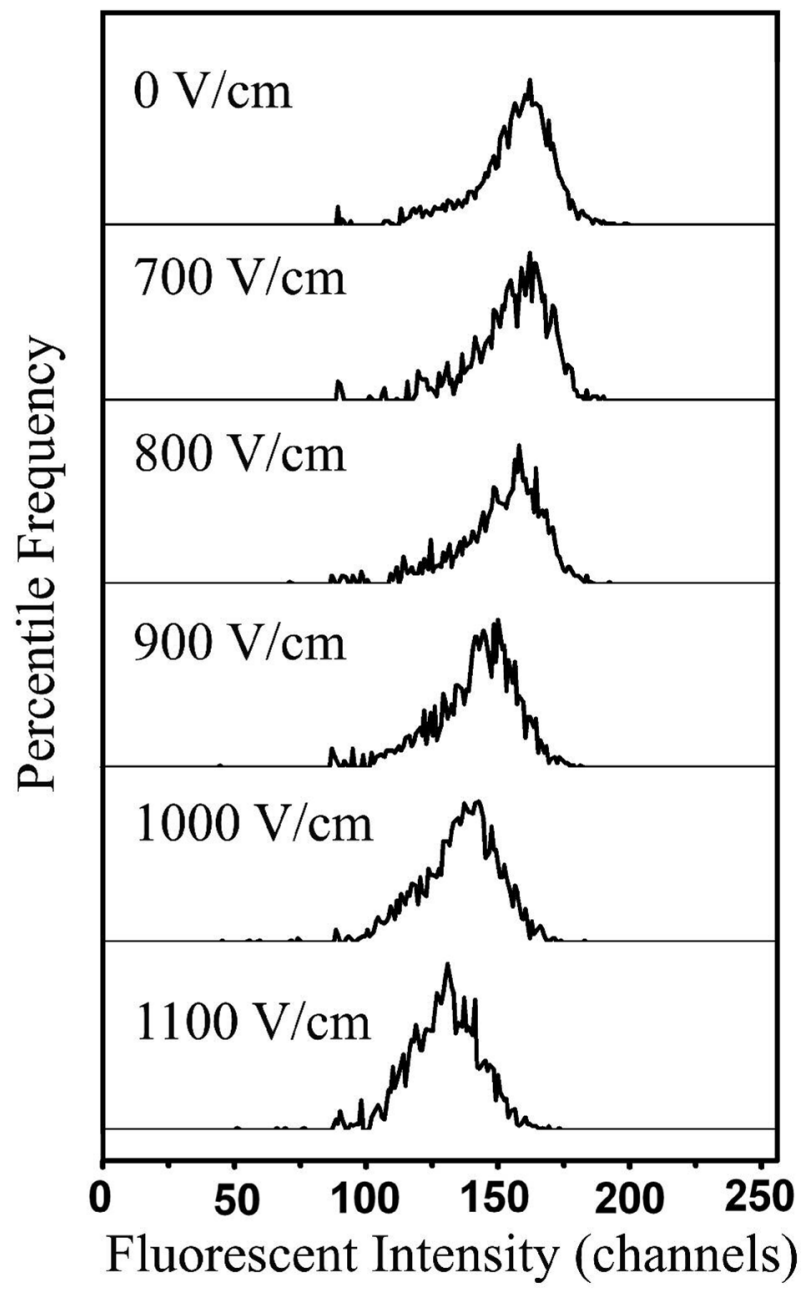

Figure 4.

The histograms of the fluorescence intensity generated by SykEGFP-DT40-Syk ${ }^{-}-\mathrm{Lyn}^{-}{ }^{-}$cells (without stimulation) processed in the microfluidic EFC device at different field intensities(0$1100 \mathrm{~V} / \mathrm{cm})$. The field duration was $60 \mathrm{~ms}$. 


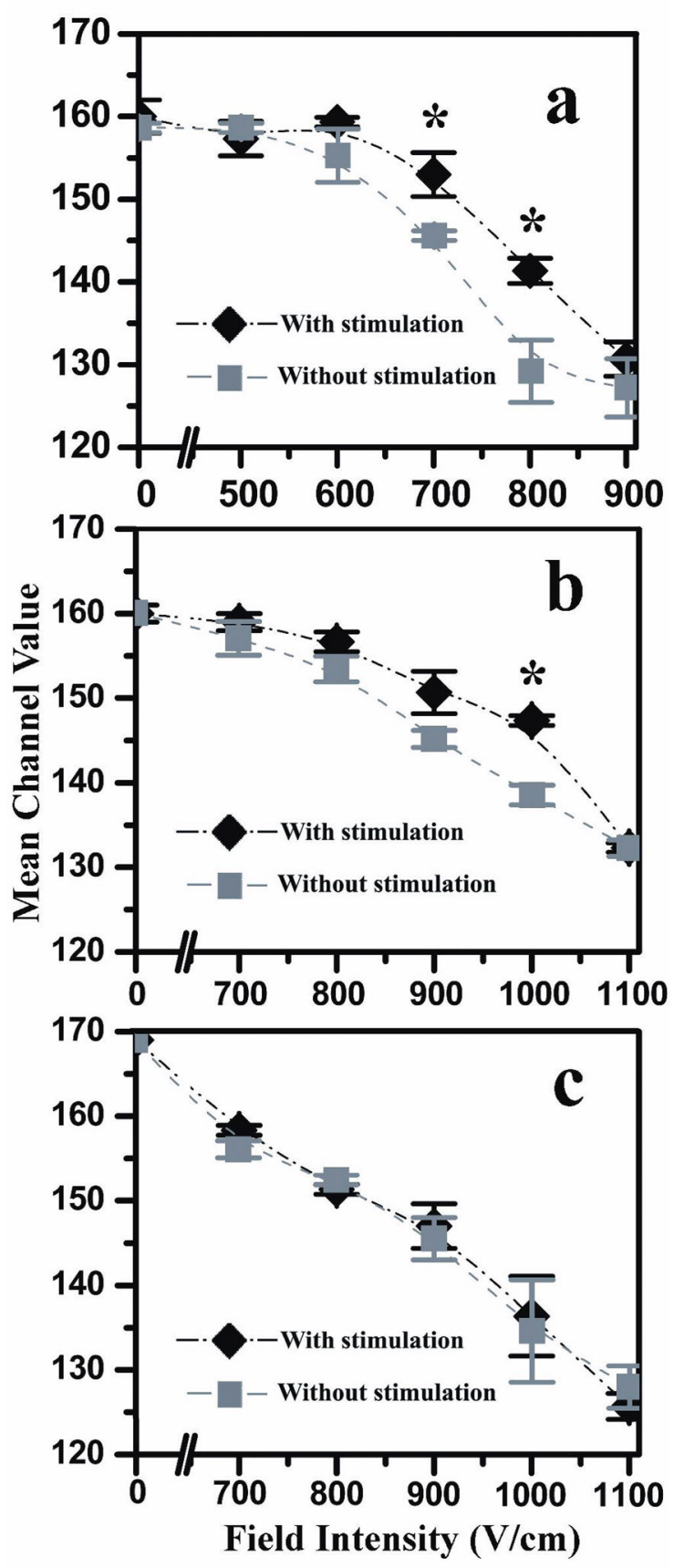

Figure 5.

The variation of the mean fluorescence intensity value of the cell population at different field intensities with and without stimulation by anti-IgM. SykEGFP-DT40-Syk ${ }^{-}$Lyn $^{-}$cells were applied in (a) and (b), while calcein AM stained DT40-Syk ${ }^{-} \mathrm{Lyn}^{-}$cells were used in (c). The data in (a) and (b) were obtained with different electroporation durations of 120 and $60 \mathrm{~ms}$, respectively. The duration in (c) was $60 \mathrm{~ms}$. The error bars were generated by carrying out the experiments in triplicate. $(*)$ indicates significant difference at $\mathrm{P}<0.01$, calculated using unpaired t test with equal variance. 